\title{
PONTE-AÉREA RIO DE JANEIRO-SÃO PAULO NO CONTEXTO DA MEGARREGIÃO: A DINÂMICA DA FLUIDEZ AÉREA SELETIVA NO TERRITÓRIO BRASILEIRO
}

\author{
THE RIO DE JANEIRO-SÃO PAULO AIR BRIDGE IN THE \\ CONTEXT OF MEGA-REGION: THE DYNAMICS OF A SELECTIVE \\ AIR FLUIDITY IN THE BRAZILIAN TERRITORY
PONT AÉRIEN RIO DE JANEIRO-SÃO PAULO DANS LE CONTEXTE
DE LA MÉGA-RÉGION: LES DYNAMIQUES DE LA FLUIDITÉ DE L'AIR SÉLECTIVE SUR LE TERRITOIRE BRÉSILIEN

\begin{abstract}
Ana Paula Camilo Pereira - Universidade Estadual de Mato Grosso do Sul - Campo Grande - Mato Grosso do Sul apaulacape@uems.br
\end{abstract}

\begin{abstract}
Resumo
A relevância de uma das principais ponte-aéreas do mundo incita uma análise pormenorizada da dinamicidade dessa fluidez seletiva. A essencialidade da ponte-aérea Rio de Janeiro-São Paulo, compreendida a partir dos aeroportos de Santos Dumont e Congonhas destaca-se, dentre outros efetivos, por se caracterizar como um importante eixo conectivo da megarregião Rio de Janeiro-São Paulo. Desse modo, a análise proposta buscou evidenciar, por meio de uma abordagem geográfica, a importância dessa rota na rede aérea brasileira, destacando 0 potencial de geração de tráfego desses aeroportos, a dinâmica territorial promovida, 0 interesse do capital nos principais fixos dessa megarregião e a unicidade desses aeroportos e dessa ligação na rede aérea brasileira. Em síntese, constata-se que a representatividade dessa rota confirma-se pela sua expressividade no número voos, pelo constante interesse do capital, pela lógica dos processos globais da reprodução capitalista e pela evolução da demanda efetiva. Mas, é sobretudo porque a megarregião Rio de Janeiro-São Paulo também não cessa a sua expansão.

Palavras-chave: Ponte-aérea. Megarregião. Rio de Janeiro-São Paulo. Aeroportos.
\end{abstract}

\section{Abstract}

The relevance of one of the busiest air routes in the world (the Air Bridge between Rio de Janeiro e São Paulo) requires a detailed analysis of its selective fluidity and dynamics. The essentiality of the air route between these two important Brazilian cities, between the airports of Santos Dumont and Congonhas, stands out, among other factors, to be characterized as an important connective axis of the Rio de Janeiro-São Paulo mega-region. Thus, the analysis of this work seeks to expose, through a statistical and theoretical approach, the importance of this route in the Brazilian air network. Emphasizing the traffic generation potential of these two airports, the territorial dynamics promoted, the interest of capital in the main airports of this mega-region and the uniqueness of these airports, as well as, of that route in the Brazilian air network. In summary, the representativeness of this route is confirmed by its expressiveness in the number of flights, by the constant interest of capital, by the logic of the global processes of capitalist reproduction and by the evolution of effective demand. However, it is mainly because the mega-region Rio de Janeiro-São Paulo also does not stop its expansion.

Keywords: Air bridge. Mega-region. Rio de Janeiro-São Paulo. Airports. 


\section{Résumé}

La pertinence de l'un des ponts aériens les plus importants au monde incite une analyse détaillée de la dynamique de cette fluidité sélective. L'essentialité du pont aérien Rio de Janeiro-São Paulo, composé des aéroports de Santos Dumont et de Congonhas, se démarque, entre autres facteurs, comme important axe de connexion de la méga-région Rio de Janeiro-São Paulo. Ainsi, l'analyse proposée cherchait à montrer, par une approche géographique, l'importance de cette liaison dans le réseau aérien brésilien, en soulignant le potentiel de génération de trafic de ces aéroports, les dynamiques territoriales promues, l'intérêt du capital pour les principaux fixes de cette méga-région et le caractère unique et de ce lien dans le réseau aérien brésilien. En résumé, la représentativité de cette route est confirmée par son expressivité dans le nombre de vols, par I'intérêt constant du capital, par la logique des processus globaux de reproduction capitaliste et par l'évolution de la demande effective. Mais c'est principalement parce que la méga-région Rio de Janeiro-São Paulo n'arrête pas également son expansion.

Mots-clés: Pont aérien. Méga-région. Rio de Janeiro-São Paulo. Aéroports.

\section{Introdução}

O setor de transporte aéreo está essencialmente relacionado à circulação territorial. A estruturação da rede ${ }^{1}$ de fluxos, no que diz respeito à funcionalidade, a conectividade e a brevidade do espaço no tempo, tem no seu conjunto técnico aeroportuário o seu principal elemento de organização da fluidez territorial ${ }^{2}$ (Arroyo, 2005) e, nesse sentido, as companhias aéreas e os aeroportos exercem importante papel na dinâmica dos fluxos.

Ao tratarmos da relação entre as companhias e os aeroportos é fundamental articularmos nessa discussão a tessitura do desenho das rotas aéreas, uma vez que empresas e aeroportos se constituem estrategicamente nessa relação, pois empreendem a fluidez, o lucro, a lógica de deslocamentos etc., a partir da estruturação das malhas de voos organizadas pelas empresas em decorrência de suas estratégias competitivas.

Sendo assim, essa organização da circulação aérea não está restrita apenas às estratégias de nível do capital, pois ocorre conjuntamente ao nível do território, o que pode ser melhor entendido como uma disputa territorial (Camilo Pereira, 2016). Em outras palavras, não basta ao capital estar presente em inúmeros aeroportos, é importante ter visibilidade nos principais aeroportos da rede aeroportuária do país.

É nessa perspectiva que as companhias aéreas brasileiras buscam freneticamente se inserir na conhecida ponte-aérea Santos DumontCongonhas $^{3}$, constituída na megarregião Rio de Janeiro-São Paulo (Lencioni, 2015), pois é a rota que define o maior número de passageiros no Brasil, conforme dados estatísticos da Agência Nacional da Aviação Civil (Anac), no ano de 2018. 
Não é aleatório que as companhias aéreas operem naqueles aeroportos de maior capacidade de geração de tráfego, uma vez que a fluidez nesses aeroportos é garantida e é desnecessário criar estratégias para promover a oferta, mas sim estratégias de direcionamento dos passageiros a optarem por uma determinada empresa aérea. Do mesmo modo, os aeroportos também necessitam que as grandes companhias tenham interesse nas operações, é um movimento cíclico. Assim, no caso dos aeroportos de Santos Dumont e Congonhas, esse movimento é tracionado pelas empresas, já que esses aeroportos, incontestavelmente, definem a rota mais atrativa do mercado aéreo brasileiro, constituindo importantes hubs ${ }^{4}$ para o setor.

Os aeroportos que estão localizados na megarregião Rio de Janeiro e São Paulo ${ }^{5}$ conformam-se como nós centrais de uma rede corporativa estratégica para o transporte aéreo que projeta, hierarquicamente, a maior oferta/demanda de fluxos, concentrando a operacionalização de companhias aéreas, malhas de voos e conexões/escalas nos principais nós dessa rede e, nesse contexto, a ponte-aérea definida pelos aeroportos de Santos Dumont e Congonhas ganha destaque.

De acordo com um levantamento organizado pela companhia de inteligência que realiza estudos estatísticos sobre transporte aéreo mundial, a Aviation Worldwide Limited (OAG), no ano de 2017, entre as principais pontes-aéreas mundiais, a ponte-aérea Santos DumontCongonhas ${ }^{6}$ esteve entre as 15 principais rotas mundiais em relação à capacidade de assento, sendo que no mesmo ano ${ }^{7}$ foi considerada a terceira em relação à frequência de voos e também a quinta rota mais movimentada do mundo em números de passageiros.

A demanda pelo transporte aéreo no Brasil é crescente. Nos últimos anos, observa-se que mais do que triplicou o uso do transporte aéreo, sendo que apenas no ano de 2012 houve uma alta de 234\% na demanda pelo setor. De acordo com o Anuário de Transporte Aéreo (ANAC, 2016), a demanda doméstica cresceu, em média, 9,8\% ao ano nos últimos dez anos.

As estatísticas da ANAC informam que no ano de 2017 a demanda doméstica do transporte aéreo de passageiros apresentou crescimento de $3,2 \%$, em relação à redução de 5,7\% no ano anterior. Este indicador cresceu 85\% entre os anos de 2008 e 2017 e com crescimento médio de 7,1\% ao ano.

Esse crescimento representou 5,5 vezes o crescimento do Produto Interno Bruto (PIB) brasileiro e mais de seis vezes o da população do país 
(ANAC, 2018). Soma-se ainda o fato de que a ponte-aérea Rio de JaneiroSão Paulo é mais movimentada da América do Sul, sendo que a segunda rota de maior movimento é a que liga Lima a Cuzco no Peru (2,47 milhões de passageiros), a qual apresenta quase metade do número de passageiros quando comparada com a ponte-aérea brasileira.

Ao analisar a rede de transporte aéreo brasileiro, nota-se que esses elementos revelam a estruturação e organização do território a partir desse modal e da rede de aeroportos localizados nessas metrópoles, estabelecendo os principais eixos de conexão do país.

Dessa forma, o aeroporto de Congonhas, localizado na capital paulista, e o aeroporto de Santos Dumont, localizado na capital fluminense, vem agregar valor a essa dinâmica aeroviária, representando a principal rota brasileira em número de voos e passageiros no Brasil na atualidade, o que pode ser constatado pelas análises estatísticas realizadas pela ANAC (2017).

A ANAC (2017) ainda destaca que o total de passageiros em voos domésticos foi de 90,6 milhões, no ano de 2017, sendo que somente na ponte-aérea Santos Dumont-Congonhas esse montante corresponde a mais de 4,1 milhões de passageiros transportados, ou seja, essa rota representou no mesmo ano cerca de $4,5 \%$ do total de voos nacionais.

A partir dessa abordagem, este artigo tem como objetivo apresentar uma análise sobre os fluxos aéreos na ponte-aérea Santos DumontCongonhas, reconhecendo a importância da constituição da megarregião Rio de Janeiro-São Paulo para a promoção da maior e mais intensa fluidez aérea do país. Temos como ponto essencial destacar a substancialidade desse eixo com prioridade para os referidos aeroportos, mesmo diante da presença de outros fixos aeroportuários que se constituem no mesmo eixo de circulação.

Tendo tais elementos como problemática a ser discutida, destacamos os seguintes pontos de abordagem: a essencialidade do caráter único e seletivo desses aeroportos que constituem a ponte-aérea brasileira, associada à importância da megarregião Rio de Janeiro-São Paulo.

Essas análises se estruturam metodologicamente a partir de dados estatísticos recentes da evolução do número de passageiros nessa rota (2011-2017) disponibilizados pela Anac por meio do Anuário de Transporte Aéreo e da Lei de Acesso à Informação. Soma-se a isso uma pesquisa empírica obtida por meio de entrevistas com as companhias aéreas, o que resulta numa análise sobre o papel das estratégias empresariais em termos 
de posicionamento geográfico e de mercado nos referidos aeroportos brasileiros.

Por meio da correlação dessas análises apresenta-se uma leitura sobre os resultados obtidos relativos a inegável dimensão da ponte-aérea Rio de Janeiro-São Paulo na dinâmica do transporte aéreo brasileiro, no intuito de contribuir com as pesquisas geográficas atuais referentes a constituição da megarregião Rio de Janeiro-São Paulo na perspectiva da fluidez aérea.

A ponte-aérea Santos Dumont-Congonhas no contexto da constituição da megarregião Rio de Janeiro-São Paulo

A formação social e econômica do Brasil reforça a importância de São Paulo e Rio de Janeiro no contexto histórico e de desenvolvimento do país, sobretudo a partir do século XVIII mediante a concentração de riqueza e de população nesse eixo de circulação. Nessa perspectiva, a configuração territorial de uma mancha urbana constituída pelo eixo de maior poder econômico do país, acentuou a preponderância dessa relação entre o Rio de Janeiro e São Paulo, afirmando-se a partir de uma megarregião desenvolvida por uma urbanização regional.

Embora não seja o foco principal, a conceituação da megarregião se coloca como um ponto elementar para essa abordagem, pois identifica geográfica e estrategicamente a localização de dois importantes fixos aeroportuários no Brasil, Santos Dumont e Congonhas.

Nesse sentido, a contextualização teórico-conceitual referente a megarregião tem como aporte as análises de Lencioni (2015) para quem o conceito de megarregião pode ser definido pela ideia síntese de uma nova fase da urbanização ou de estágio superior do desenvolvimento metropolitano, a pós-urbanização. Assim, a megarregião Rio de JaneiroSão Paulo consiste na mais importante região urbana do hemisfério sul e se confirma como a expressão da urbanização contemporânea no Brasil.

Para Lencioni (2017, p. 11), “a forma híbrida da urbanização regional configura uma megarregião com intensa integração produtiva, forte interação com a economia global e grande densidade dos movimentos pendulares”. Agrega-se a essa relação à integração pela circulação aérea e, consequentemente, esses aeroportos imprimem uma peculiar influência na constituição dessa megarregião e de suas relações globais. 
O que é importante frisar é que a megarregião Rio de Janeiro-São Paulo se constitui como centro. Não como centro geográfico do país, porque, de fato, não o é. E nem como centro econômico do Brasil, embora o seja. Mas como centro que coloca em conexão o capital que aqui se reproduz com o conjunto da produção capitalista em escala global [...]. Nessa nebulosa urbana que conforma uma megarregião, os processos de metropolização do espaço anunciam um novo ciclo urbano em que o espaço é fortemente integrado globalmente. Pode parecer que a integração é decorrente das infraestruturas, mas de fato ela é muito mais um resultado das interações sociais, destacando-se aí a integração entre o capital e o trabalho e entre os capitais que aqui são reproduzidos e que guardam vínculos estreitos com os processos globais da reprodução capitalista (LENCIONI, 2017, n. p.).

O Mapa 1 a seguir ilustra a configuração dessa delimitação geográfica constituída pela conformação entre o Rio de Janeiro e São Paulo, na qual, segundo a autora supracitada, os fluxos e toda a infraestrutura de circulação estruturam e integram territorialmente dando coesão a esse recorte espacial

Mapa 1 - Megarregião Rio de Janeiro-São Paulo (2019)

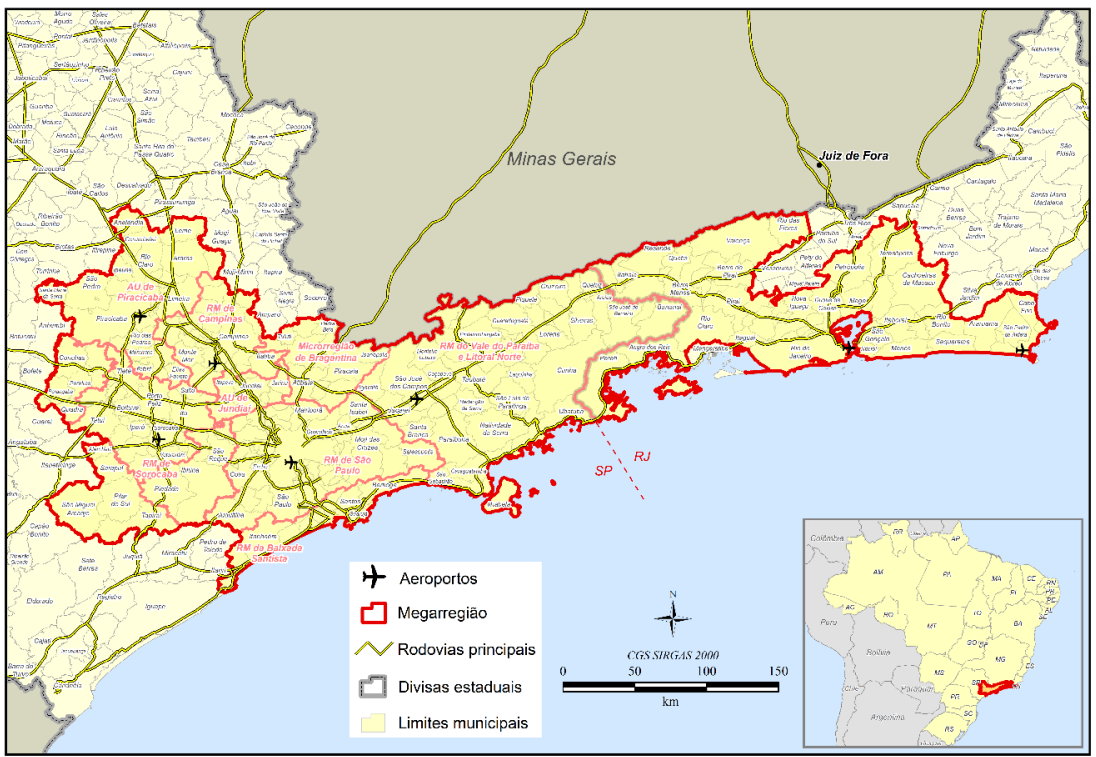

Fonte: Adaptado de Lencioni (2015). Produção Cartográfica: Rafael Oliveira Fonseca (2018). 
Desse modo, a correlação entre a constituição da megarregião Rio de Janeiro-São Paulo com a configuração do setor de transporte aéreo brasileiro, especificamente com a ponte-aérea Santos Dumont-Congonhas impõe-se por uma lógica que é produto e, ao mesmo tempo, produz as interações espaciais, mas também em função dessa rota aérea projetar dinâmicas econômicas que refletem nos processos globais da reprodução capitalista.

No Brasil, há uma rede de aeroportos consideravelmente extensa que demonstra a tendência estrutural da rede urbana de permanência de sua forma, caracterizada pelas concentrações populacionais e de riqueza no território, que se efetiva pelas ligações mais densas entre as cidades mais dinâmicas e ativas economicamente, como é caso dos aeroportos de Santos Dumont e Congonhas, no Rio de Janeiro e em São Paulo, respectivamente.

Essas cidades possuem aeroportos, que em geral, desenvolvem-se pela própria dinâmica das áreas metropolitanas onde estão localizadas, daí compreender a relação estabelecida entre a hierarquia aeroportuária e a hierarquia urbana, principalmente em termos de população, centralidade e riqueza.

De acordo com Pons e Reynes (2004), a localização dos maiores sistemas aeroportuários, bem como o maior número de aeroportos de maior categoria, está claramente relacionada com a localização das maiores aglomerações urbanas, mas também, e em maior medida, com as maiores aglomerações econômicas.

No caso brasileiro, essa demanda pelo sistema aeroportuário também está relacionada à maior aglomeração urbana, uma vez que o tráfego aéreo brasileiro revela, de maneira extremamente nítida, as redes hierarquizadas (Théry, 2003), como é o caso do Rio de Janeiro e São Paulo. A rede geográfica de fluxos do transporte aéreo é um aspecto indissociável da rede urbana e assume, em geral, caráter hierárquico (IBGE, 2007).

Os principais aeroportos de maior movimentação aérea estão localizados nas principais cidades brasileiras, onde a demanda é substancialmente maior. Essa rede urbana hierarquizada, projeta para o setor aéreo a mesma lógica de classificação. Conforme Théry (2003, p. 19) destaca, "os mapas de fluxos desenham de maneira muito clara as redes hierarquizadas refletindo a estrutura centralizada do país”. Essa estrutura centralizada do país se confirma, preponderantemente, pela megarregião Rio de Janeiro-São Paulo. 
A Região Metropolitana de São Paulo (RMSP) conta com mais de 21 milhões de habitantes situados nos 39 municípios (EMPLASA, 2016). Já a Região Metropolitana do Rio de Janeiro (RMRJ) possui população de mais 12 milhões de habitantes e 21 municípios (IBGE, 2018). A somatória dessas regiões representa aproximadamente $16 \%$ da população do país, demonstrando o impacto populacional dessas duas regiões altamente populosas o que também se incide no transporte aéreo, sobretudo quando se considera que Rio de Janeiro e São Paulo definem a principal rota do país.

Rio de Janeiro e São Paulo funcionam como um centro de acumulação do capital e seus principais aeroportos interessam particularmente ao setor empresarial, pois seus aeroportos funcionam como instrumentos de valorização do capital para as companhias.

Evidentemente que cada aeroporto possui uma especificidade que não é apenas característica do fixo em si. Rio de Janeiro e São Paulo e suas regiões metropolitanas, por exemplo, têm notáveis características que estimulam o maior interesse das companhias aéreas, uma vez que estabelece o maior conjunto urbano do país, que integra a megarregião. A pujança em relação às ligações determinadas histórica e economicamente pela gestão empresarial, de negócios, eventos etc., faz com que essas regiões metropolitanas e seus aeroportos suplantem dominantemente uma posição hierárquica superior, tanto na rede urbana como na rede aérea.

Estudos realizados pela Secretaria de Aviação Civil, denominados de "Brasil que voa" (Brasil, 2018) mostram que dentre as 10 rotas brasileiras que apresentam maior número de passageiros, os aeroportos da RMSP estão presentes em nove dessas 10 rotas mais movimentadas. Ainda de acordo com os estudos "Brasil que voa (Brasil, 2018), a ponte-aérea Santos Dumont-Congonhas deteve 63\% dos passageiros transportados entre Rio de Janeiro e São Paulo no ano de 2015.

Além disso, a evolução do número de passageiros transportados nessa rota, apesar de uma simbólica queda em 2013 e 2016, corrobora sua predominância em décadas como a principal rota do Brasil, conforme demonstra a Tabela 1. 
Tabela 1 - Evolução e taxa de crescimento do número de passageiros na ponte-aérea Santos Dumont-Congonhas (2011-2017)

\begin{tabular}{c|c|c}
\hline Anos & Passageiros transportados & Taxa de crescimento \\
\hline 2011 & 3.867 .230 & - \\
\hline 2012 & 3.985 .155 & $3,0 \%$ \\
\hline 2013 & 3.980 .821 & $-0,1 \%$ \\
\hline 2014 & 4.000 .926 & $0,5 \%$ \\
\hline 2015 & 4.047 .159 & $1,1 \%$ \\
\hline 2016 & 3.906 .171 & $-3,4 \%$ \\
\hline 2017 & 4.093 .857 & $4,8 \%$ \\
\hline
\end{tabular}

Fonte: Anuários Estatísticos (ANAC, 2011, 2012, 2013, 2014, 2015, 2016 e 2017).

Essa evolução do número passageiros na ponte-aérea brasileira não é atual. De acordo com estudos do IBGE (2013), o que se pode constatar é que desde os anos de 1970 há uma concentração da fluidez na região Sudeste, mas que progressivamente foi espraiando para o Sul e Nordeste do país.

A Figura 1 a seguir mostra a concentração de ligações aéreas no Sudeste, com foco para Rio de Janeiro e São Paulo a partir dos anos de 1970 até os anos 2005. A expansão da rede aérea brasileira é evidente ao longo dos anos para as demais regiões do país, no entanto, essa expansão também se amplia no recorte analisado, o que demonstra o acompanhamento a partir da ponte-aérea em relação ao processo de formação territorial e econômico do país, considerando nessa abordagem, a descentralização urbano-industrial, a abertura de outras frentes pioneiras, a centralização da gestão empresarial e tecnológica na megarregião, dentre outros fatores. 
Figura 1 - Ligações aéreas de passageiros no Brasil (1972, 1980, 1990, 1995, 2000 e 2005)

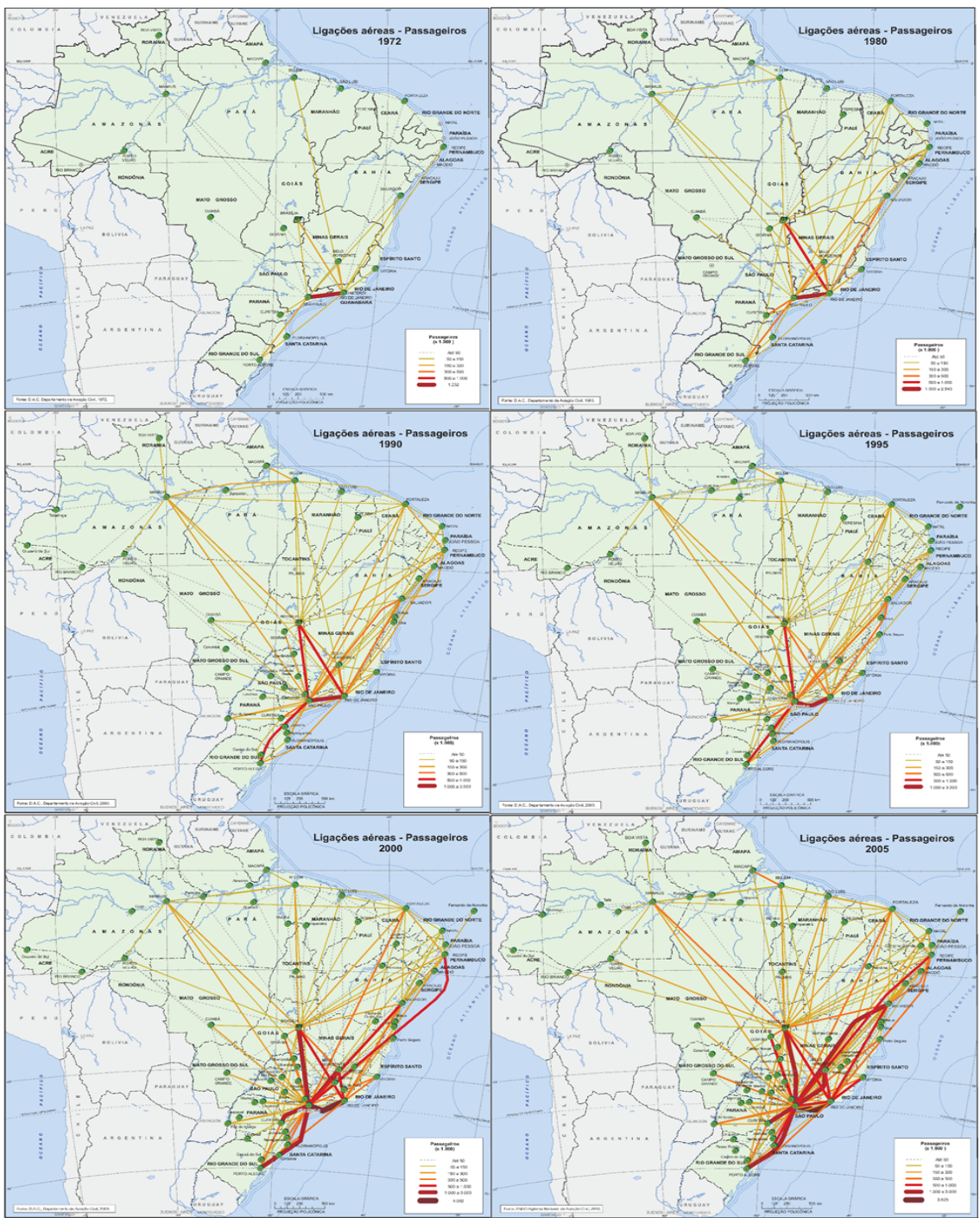

Fonte: IBGE (2013).

No Gráfico 1 é possível observar a posição da ponte-aérea Santos Dumont-Congonhas em relação as demais rotas de maior movimento 
no país. Os dados elucidam o expressivo número de passageiros que utilizam essa ligação, e mesmo quando comparado ao segundo trecho mais movimentado do Brasil, a ligação entre os Aeroportos de Congonhas e Brasília8, constata-se uma diferença superior que corresponde a quase o dobro de passageiros transportados.

Além disso, vale destacar que percentualmente a ponte-aérea Rio de Janeiro-São Paulo é a que demonstra o maior crescimento no número de passageiros quando se compara 2016 e 2017, sendo que no primeiro ano foram transportados pouco mais de 3,9 milhões de passageiros e em 2017, foram transportados quase 4,1 milhões de passageiros em voos regulares comerciais.

Gráfico 1 - Passageiros transportados nas 20 rotas mais movimentadas do Brasil (2016-2017)

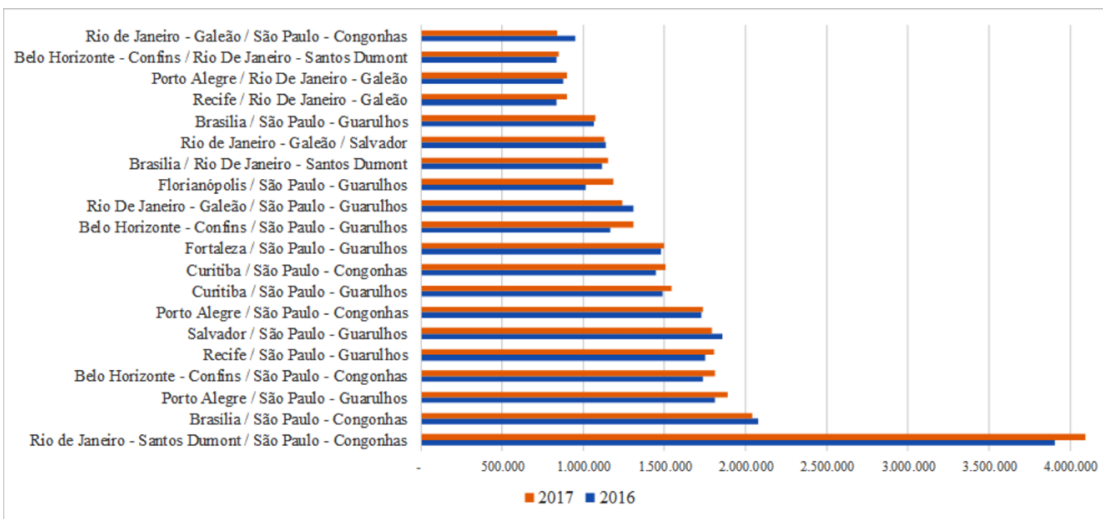

Fonte: ANAC (2018).

Salienta-se que a localização dos aeroportos no tecido urbano é extremamente relevante no ordenamento territorial da rede aérea brasileira, daí compreende-se porque outros aeroportos localizados na megarregião Rio de Janeiro-São Paulo não sistematizam um potencial concorrente para os aeroportos de Santos Dumont e Congonhas, ainda que se configurem na mesma rota aérea.

Apesar da megarregião possuir outros aeroportos de latente importância na rede aeroportuária brasileira, a destacar: o Aeroporto Internacional do Galeão, o Aeroporto Internacional de Guarulhos e o Aeroporto Internacional de Viracopos, o que define a configuração aérea 
desses fixos é a dinâmica geográfica de localização dos mesmos em suas respectivas regiões metropolitanas, bem como de distribuição dos voos, que em grande medida, foi constituída historicamente, mas também em razão de algumas peculiaridades, como veremos adiante.

A característica peculiar de Santos Dumont e Congonhas se fundamenta por dois fatores essenciais para compreender porque esses aeroportos definem essa ponte-aérea. Primeiro, a localização centralizada desses dois aeroportos nas cidades do Rio de Janeiro e de São Paulo; segundo o que complementa o primeiro fator, o perfil do passageiro que mais utiliza essa rota, o que a torna seletiva em termos de passageiro e precificação.

De acordo com entrevistas ${ }^{9}$ realizadas com as companhias aéreas brasileiras, $80 \%$ dos passageiros que correspondem a demanda efetiva nesse segmento são executivos à negócio, que geralmente, se deslocam entre as duas metrópoles (muitas vezes diariamente). Esse perfil de passageiro demanda um deslocamento rápido não só durante o voo, mas também em solo, em geral, suas atividades executivas encontram-se localizadas nos centros das duas grandes cidades, envoltas às principais áreas de hotéis e também próximas às principais áreas empresariais, o que engendra vantagens comparativas a esses fixos aeroportuários em relação aos seus principais "concorrentes”, como o Galeão, no Rio de Janeiro, e Guarulhos, em São Paulo.

Comparativamente, o Aeroporto de Guarulhos está distante aproximadamente $21 \mathrm{~km}$ do centro velho de São Paulo, tendo como referência a Praça da Sé, e dista 37 km do centro empresarial da região da Avenida Engenheiro Luís Carlos Berrini, um dos principais centros empresariais de São Paulo. O Aeroporto do Galeão dista aproximadamente $12,2 \mathrm{~km}$ do centro do Rio de Janeiro, definindo como referência a Praça Tiradentes. Já o aeroporto de Congonhas está cerca de 8,5 km da Praça da Sé e $6 \mathrm{~km}$ da região da Berrini e o Aeroporto de Santos Dumont dista $2 \mathrm{~km}$ do centro da cidade do Rio de Janeiro.

Assim, o deslocamento entre as capitais fluminense e paulista, se realiza de forma mais diligente pelos aeroportos de Santos Dumont e Congonhas, pelas suas respectivas localizações geográficas centralizadas nas duas metrópoles. Isso é melhor compreendido pelas distâncias dos aeroportos em relação ao centro dessas cidades, conforme o Mapa 2. 
Mapa 2 - Localização dos aeroportos de Congonhas, Guarulhos, Santos Dumont e Galeão nas metrópoles do Rio de Janeiro e São Paulo

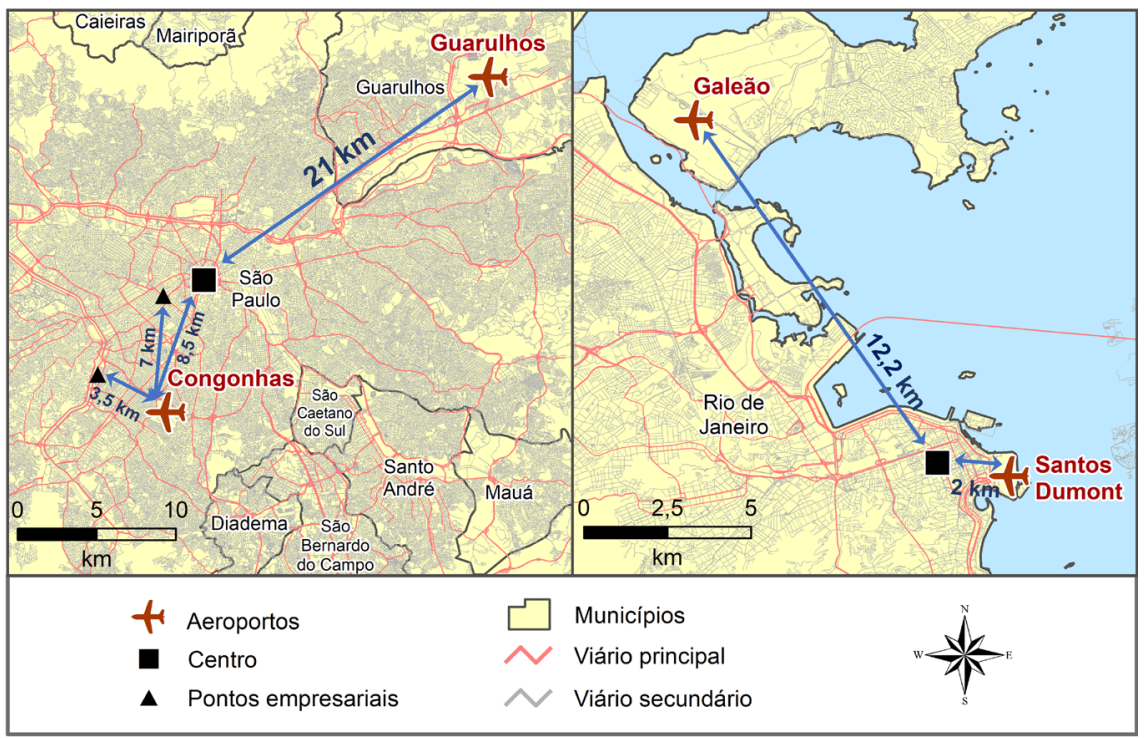

Organização: Camilo Pereira (2018); Produção Cartográfica: Rafael Oliveira Fonseca (2018).

Além disso, esses aeroportos desenvolveram diferentes características que lhe são próprias em razão também da localização geográfica, da designação dos voos e dos aeroportos (se nacionais e/ou internacionais), oriundas desde o momento de suas instalações, uma vez que aeroportos mais recentes são instalados em áreas mais distantes dos centros urbanos, como no caso dos aeroportos do Galeão e de Guarulhos.

Em resumo, ao nos direcionarmos para essas características podemos constatar a particularidade desses fixos aeroportuários quando comparados aos demais aeroportos também localizados na megarregião, o que demonstra a unicidade dessa ligação aérea em relação as demais rotas, o que a define como singular e lhe atribui certa exclusividade, mesmo com a operação dos demais aeroportos nessa mesma rota aérea. Tal fato incide diretamente nas estratégias de organização da malha das companhias aéreas e reflete, sobretudo, no poder territorial que estas empresas imprimem no mercado da aviação civil. 
A ponte-aérea Rio de Janeiro-São Paulo: o poder territorial na perspectiva empresarial

Na perspectiva de análise sobre o poder territorial das empresas aéreas nesses aeroportos e, mais especificamente na ponte-aérea Santos Dumont-Congonhas, é necessário fazer a articulação entre a participação de mercado (market share ${ }^{10}$ ) das principais companhias aéreas nacionais e a principal demanda que caracteriza esses fixos, ou seja, a ponte-aérea.

O poder territorial tem relação direta com a participação de mercado, em outras palavras, se uma companhia tem um grande número de slots $^{11}$, proporcionalmente isso influi na expressividade do número de passageiros que a empresa consegue transportar. Quando se analisa essa relação numa rota estratégica como é a ponte-aérea, compreende-se que a companhia que tem significativo número de slots e passageiro, tem um poder territorial de mercado representativo, ou seja, uma maior market share nessa rota estratégica.

As principais empresas aéreas no ano de 2017 em operação no Brasil foram: Gol Linhas Aéreas Brasileiras, Latam Airlines Group (antiga TAM Linhas Aéreas), Azul Linhas Aéreas e Avianca Linhas Aéreas, mas nem todas essas companhias detém o poder de operação na rota Santos Dumont-Congonhas.

A ponte-aérea Rio de Janeiro-São Paulo, por ser a rota mais movimentada do país em termos de volume de passageiros e frequência/ dia, obviamente é uma das mais disputadas pelas empresas aéreas nacionais, e isso também reflete na distribuição de slots em Santos Dumont e em Congonhas.

O sistema de alocação de slots é definido como uma forma de contornar a falta de capacidade infraestrutural dos aeroportos em relação à demanda e oferta. A configuração empresarial das companhias nesse sistema, permite compreender que as grandes empresas são favorecidas na distribuição dos slots nos aeroportos de importante fluidez, o que contribuiu para expansão da capacidade empresarial, seja em relação à frequência de voos, ao planejamento de suas malhas aéreas, bem como a diminuição da concorrência com outras companhias, sobretudo as de pequeno e médio porte ou as empresas entrantes.

De acordo com relatório da própria entidade reguladora do setor, a ANAC, as companhias aéreas Latam e Gol possuem juntas $90 \%$ de slots nos aeroportos brasileiros, o que representa um percentual extremamente 
elevado de voos nos principais aeroportos do país, sobretudo na ponteaérea Rio de Janeiro-São Paulo. Isso significa que, apesar da expressividade adquirida por outras companhias brasileiras, tal como a Azul, a Gol e a Latam continuam concentrando o poder territorial de atuação no mercado aéreo, com destaque para a ponte-aérea em análise.

Essas empresas aéreas empreendem uma intensa concorrência (porque cada empresa aérea busca promover estratégias que possibilite ampliar o número de frequências nesses aeroportos) e a competitividade (já que a maior participação em Santos Dumont e Congonhas garante automaticamente maior market share, em razão, principalmente, desses aeroportos empreendem a ligação mais movimentada do país).

As principais ligações domésticas destas empresas estão concentradas (quantidade de voos) e centralizadas (com origem/destino) nesses aeroportos. Em resumo, é a ponte aérea operada entre os aeroportos de Santos Dumont e Congonhas, aeroportos exclusivamente domésticos, que suplanta a maior parte dos passageiros que passam por esses dois aeroportos.

Tal fato é evidenciado pela participação de mercado das empresas, a liderança no mercado doméstico em termos de demanda manteve-se com as companhias Gol e Latam. O Gráfico 2 a seguir mostra a participação de mercado dessas empresas no primeiro semestre do ano de 2018 na ponteaérea Santos Dumont-Congonhas, demonstrando o duopólio existente entre a Gol e a Latam, com considerável participação em relação a Avianca. 
Gráfico 2 - Percentual de passageiros por companhia aérea na ponte-aérea Rio de Janeiro-São Paulo (jan.-jul. 2018)

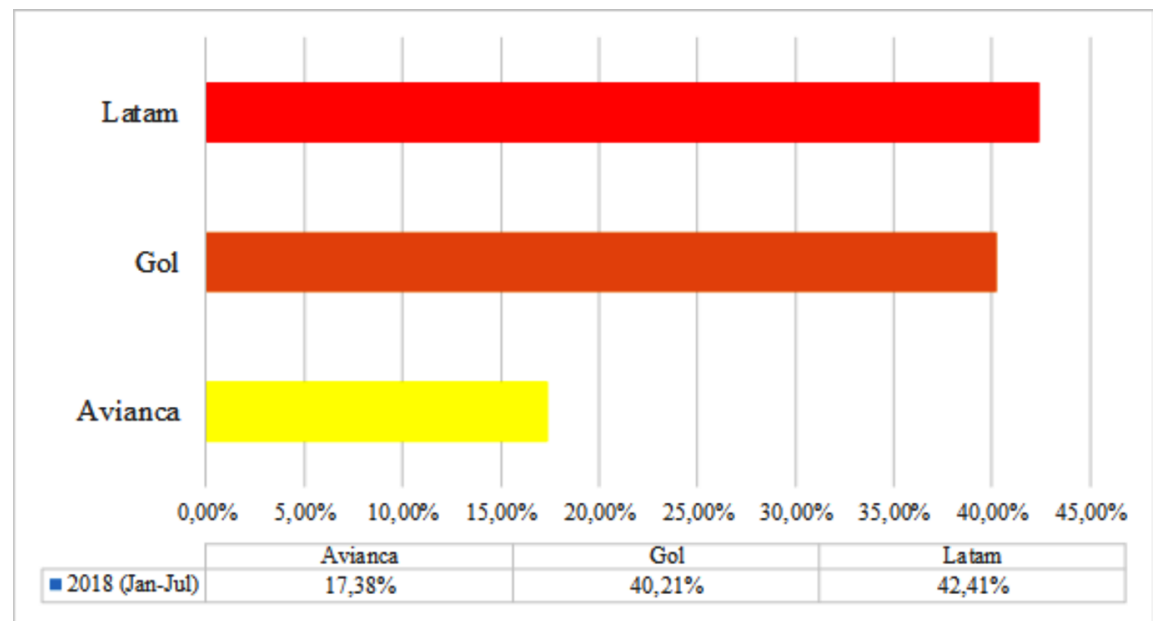

Fonte: ANAC (2018).

Devido às restrições de números de slots nesses aeroportos, a empresa Azul passou a oferecer estrategicamente uma opção de concorrência no eixo Rio de Janeiro-São Paulo, empreendendo esta ligação entre os aeroportos de Viracopos/Campinas e Galeão/Rio de Janeiro, definindo-a como a ponte-aérea da Azul.

Apesar de movimentar um número de passageiros muito abaixo quando comparado com as demais empresas na rota Santos DumontCongonhas, a Azul tem obtido um relativo poder de mercado explorando o mesmo trajeto, ainda que não conecte os aeroportos base desse trecho, no entanto, promove mais uma opção para o eixo de circulação aérea.

O Gráfico 3 apresenta o número de passageiros transportados no ano de 2017 considerando para a Azul os aeroportos de Viracopos-Galeão e para as demais companhias a conexão entre os aeroportos Santos DumontCongonhas. Nota-se que a unicidade da tradicional ponte-aérea ainda é detentora de um poder de atração de passageiros bem maior que nos aeroportos utilizados pela Azul. 
Gráfico 3 - Número de passageiros da companhia Azul na rota Viracopos-Galeão e número de passageiros das companhias Avianca, Gol e Latam na rota Santos Dumont-Congonhas (2017)

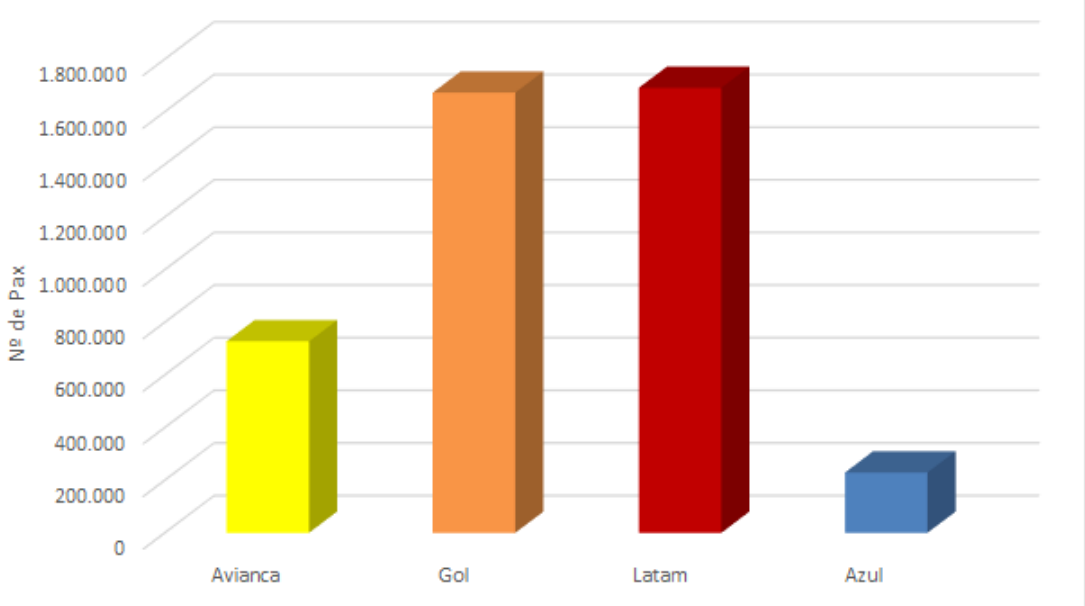

Fonte: ANAC (2017).

De forma geral, ainda que os fixos aeroportuários sejam um dos principais fatores que define o poder de mercado, a receita e a visibilidade da marca interferem na definição da malha de voos e nas estratégias das companhias. Por exemplo, o que se coloca como primordial nesse momento à Azul é estar presente nessa ligação que conecta a megarregião, daí a empresa buscar uma estratégia alternativa para se manter nessa rota.

Assim, a megarregião Rio de Janeiro-São Paulo e a operacionalidade dos aeroportos de Santos Dumont e Congonhas definem o principal eixo de negócios do país, cada qual com funções específicas e suas vantagens competitivas que refletem diretamente no interesse e na criação de estratégias pelas companhias aéreas que operam nesses aeroportos, o que influi diretamente na concorrência tanto entre as empresas aéreas, quanto entre os aeroportos.

Em síntese, independentemente das funções e especificidades que esses fixos aeroportuários desenvolvem, é notória que a participação deles no conjunto total do setor de transporte aéreo brasileiro confirma não apenas a importância desses centros urbanos e da constituição da megarregião no sistema aeroportuário doméstico, mas confere uma dinâmica intrínseca aos seus aeroportos, fatos justificados pela intensidade de frequências 
diárias e pelo crescente volume de passageiros transportados com origem/ destino nesses aeroportos, o que promove uma particular dinâmica de fluxos econômicos no setor aéreo brasileiro e reafirma a magnitude da constituição da megarregião Rio de Janeiro-São Paulo.

\section{Considerações finais}

Cada aeroporto exerce um poder sobre as companhias aéreas e viceversa. Isso se dá porque os aeroportos estão territorialmente localizados em pontos estratégicos, o que faz com que as empresas aéreas se utilizem de estratégias particulares em cada aeroporto.

Não é casual fazer de Santos Dumont e Congonhas a principal ponte-aérea do país, esses aeroportos possuem elementos adjacentes que permitem explorá-los dessa forma, dentre esses elementos, sobrepõem-se o fato de estarem localizados nas duas principais cidades do país, na principal megarregião da América do Sul. Improvável seria obter o mesmo volume de passageiros se as empresas aéreas quisessem desenvolver essa ponte-aérea entre quaisquer outros centros urbanos do país.

Nesse sentido, a análise expressa neste artigo ratifica a relevância da ponte-aérea Santos Dumont-Congonhas na megarregião Rio de JaneiroSão Paulo. Os elementos apresentados juntamente com as informações estatísticas dos órgãos vinculados ao transporte aéreo brasileiro, reforçam a dinâmica econômica empreendida pelas principais metrópoles do país, projetando a importância desse eixo econômico que é refletido hierarquicamente no setor aéreo.

Estar presente nesses dois aeroportos significa para o segmento empresarial ter um domínio de mercado capaz de promover uma maior dinâmica da concorrência na rede aérea brasileira, daí o incessante interessante e imbróglio entre o Governo (concessor da autorização de slots em aeroportos) e as principais companhias aéreas do país, que estrategicamente acirram a dinâmica competitiva por esses aeroportos, o que é compreensível, já que são os principais hubs do país, de representativa demanda, gerando, por consequência, maior receita e visibilidade às empresas.

Ressalta-se que mesmo considerando os problemas relativos ao acesso, a mobilidade, ao tempo de embarque e desembarque em voos de curta duração, como os da ponte-aérea Santos Dumont-Congonhas, o aumento de passageiros é progressivo. O montante de passageiros no 
eixo Rio de Janeiro-São Paulo (considerando os aeroportos analisados) registrou no ano de 2017 a maior marca de passageiros transportados. Além disso, Congonhas foi responsável por 10,8\% do total de decolagens no Brasil e Santos Dumont, registrou 5,8\%, sendo o $2^{\circ}$ e o $6^{\circ}$ aeroportos respectivamente, em participação na quantidade de decolagens no mercado doméstico (ANAC, 2017).

Indubitavelmente, a representatividade dessa rota na rede aérea do país se confirma pela sua expressividade no número de pousos e decolagens, pelo incessante interesse do capital, pela lógica que influi também nos processos globais da reprodução capitalista e pela evolução da demanda efetiva, mas, sobretudo porque a megarregião Rio de Janeiro-São Paulo também não cessa a sua expansão.

\section{Notas}

1 Embora não se constitua elemento de discussão teórica, o conceito de rede é entendido a partir de Dias (2005) como qualquer outra invenção humana, é uma construção da sociedade que se organiza em rede, manifestando as interações espaciais nos territórios. Nessa perspectiva, entende-se que a rede de fluxos do transporte aéreo é organizada por uma matriz de infraestrutura aeroportuária que viabiliza a fluidez territorial. Nessa discussão sobre a organização espacial dos transportes e suas redes, Pons e Bey (1991) alegam que os transportes constituem um importante canal de produção das redes geográficas que promovem a circulação de bens e pessoas.

2 Nos atemos em Arroyo (2005) ao compreender a fluidez territorial como um elemento relacionado diretamente com a base material do território e associado, de acordo com a autora, com a normativas, ou seja, a regulação do território, identificada pela porosidade territorial. Tal compreensão reflete diretamente na lógica aqui evidenciada, qual seja a fluidez territorial seletiva, que define alguns territórios de interesse do capital.

3 Oficialmente, no dia 6 de julho de 1959 nasceu a ponte-aérea com a decolagem de um Convair 240 da Varig rumo ao Rio de Janeiro. "A rota passou a ser oferecida por três grandes empresas da época, Varig, Vasp e Cruzeiro de Sul, que ligavam as duas maiores cidades do Brasil com vôos escalonados alternadamente a cada 30 minutos durante o dia, com redução pela metade das freqüências no período noturno e nos fins de semana" (Camilo Pereira, 2016).

4 Hubs: constituem os pontos de ligação do transporte aéreo, ou seja, são os aeroportos onde as empresas aéreas centralizam suas operações.

5 Nesse caso, compreendemos todos aqueles aeroportos localizados na megarregião Rio de Janeiro-São Paulo, tais como os aeroportos de: Santos Dumont, Galeão, Congonhas, Guarulhos e Viracopos. Embora cada aeroporto defina uma especificidade estratégica que varia de acordo com a oferta e a demanda, mas também mediante o interesse do capital, esses fixos aeroportuários, de forma geral, constituem-se como os principais hubs da rede aérea brasileira e, em grande medida, a importância se dá pela localização na megarregião. 
6 É importante ressaltar que as ligações entre os aeroportos de Guarulhos e do Galeão, ainda que conectem o mesmo trecho (origem-destino), não compreende a definição de ponte-aérea, histórica e operacionalmente conhecida pelos aeroportos de considerados nesta análise.

7 No ano de 2017, as duas principais pontes-aéreas do mundo em relação à frequência de voos foram respectivamente Seul Gimpo-Jeju, na Coréia do Sul e Melbourne-Sidney, na Austrália.

8 De acordo com os dados estatísticos da ANAC (2017), a segunda rota mais movimentada é a ligação entre Brasília-Congonhas, com cerca de 2 milhões de passageiros. A terceira e a quarta rota fazem a ligação Porto Alegre-São Paulo (Guarulhos) e Belo Horizonte (Confins) -Congonhas, com mais de 1,8 milhão cada trecho.

9 As entrevistas foram realizadas no ano de 2014 com diretores executivos das empresas Gol Linhas Aéreas Inteligentes, Azul Linhas Aéreas Brasileiras e a TAM Linhas Aéreas, atual Latam Airlines Group.

10 Market share: significa "participação no mercado", isto é, a fração do mercado controlado por uma empresa ou participação no mercado nas vendas de um determinado produto (SANDRONI, 2005, p. 514).

11 Slots: denominação dada às partições de tempo em um intervalo de uma hora durante as quais apenas uma operação de pouso ou de decolagem é permitida.

\section{Referências}

ANAC. Agência Nacional da Aviação Civil. Anuário do Transporte Aéreo 2011. Brasília: ANAC, 2011. 97 p.

Agência Nacional da Aviação Civil. Anuário do Transporte Aéreo 2012.

Brasília: ANAC, 2012. 188 p.

Agência Nacional da Aviação Civil. Anuário do Transporte Aéreo 2013. Brasília: ANAC, 2013. 207 p.

Agência Nacional da Aviação Civil. Anuário do Transporte Aéreo 2014. Brasília: ANAC, 2014. 237 p.

Agência Nacional da Aviação Civil. Anuário do Transporte Aéreo 2015. Brasília: ANAC, 2015. 232 p.

Agência Nacional da Aviação Civil. Anuário do Transporte Aéreo 2016. Brasília: ANAC, 2016. 228 p.

Agência Nacional da Aviação Civil. Anuário do Transporte Aéreo 2017. Brasília: ANAC, 2017. 223 p.

ARROYO, M. Fluidez e porosidade do território brasileiro no contexto da integração continental. In: M. L. Silveira (Org.). Continente em chamas: globalização e território na América Latina. Rio de Janeiro: Civilização Brasileira, 2005. p. 211-242.

BRASIL. Secretaria da Aviação Civil. Brasil que voa. 2018. Disponível em: <http://www.aviacao.gov.br/obrasilquevoa $>$. Acesso em: 18 nov. 2018. 
CAMILO PEREIRA, A. P. Asas da centralidade em céus conhecidos: a dinâmica empresarial do transporte aéreo no território brasileiro. São Paulo: Annablume, 2016.

DIAS, L. C. Os sentidos da rede: nota para discussão. In: DIAS, L. C; SILVEIRA, R. L. L. (Org.). Redes, sociedades e territórios. Rio Grande do Sul: EDUNISC, 2005. p. 11-28.

IBGE. Instituto Brasileira de Geografia e Estatística. Regiões de Influência das Cidades. Rio de Janeiro: IBGE, 2007. 201 p.

. Instituto Brasileira de Geografia e Estatística. Redes e fluxos do território: ligações aéreas 2010. Rio de Janeiro: IBGE, 2013. 66 p.

LENCIONI, S. Urbanização difusa e constituição de uma megarregião: o caso de São Paulo-Rio de Janeiro. E-metropolis, Rio de Janeiro, n. 22, Ano 6, p. 6-15, 2015. Disponível em: <http://emetropolis.net/artigo/167?name=urbanizacaodifusa-e-a-constituicao-de-megarregioes-o-caso-de-sao-paulo-rio-de-janeiro $>$. Acesso em: 17 nov. 2018.

. A megarregião Rio de Janeiro-São Paulo. Observatório das Metrópoles, 2017. Disponível em: < http://observatoriodasmetropoles.net.br>. Acesso em: 23 mar. 2019.

OAG AVIATION WORLDWIDE. On-time performance for airlines and airports and Top 20 busiest 2017. Disponível em: <www.oag.com/hubfs/Free Reports/ Punctuality_League/2018/PunctualityReport2018.pdf/> Acesso em: 19 dez. 2018.

PONS, J. M. S.; BEY, J. M. Petrus. Geografia de redes y sistemas de transportes. Madrid, Espanha: Editorial Sintesis, 1991.

PONS, J. M. S.; REYNES, J. M. M. Geografía de los Transportes. Palma de Mallorca, Universitat de les Illes Balears. Madri: Ariel, 2004.

SANDRONI, P. Dicionário de economia do século XXI. Rio de Janeiro: Record, 2005.

SÃO PAULO. Empresa Paulista de Planejamento Metropolitano. Macrometrópole Paulista, São Paulo, 2016.

THÉRY, H. O transporte aéreo no Brasil: asas da centralidade. Mercator, Fortaleza, v. 2, n. 3, p. 19-25, 2003. Disponível em: <http://www.mercator.ufc.br/ mercator/article/view/160>. Acesso em: 23 nov. 2018.

Ana Paula Camilo Pereira - Graduada em Geografia pela Universidade Federal da Grande Dourados. Mestre em Geografia pela Universidade Estadual Paulista, Campus de Presidente Prudente. Doutora em Geografia Humana pela Universidade de São Paulo. Atualmente é docente do curso de Geografia e do Programa de Pós-Graduação Stricto Sensu Mestrado Profissional em Educação da Universidade Estadual de Mato Grosso do Sul, na Unidade Universitária de Campo Grande. (D) http://orcid.org/0000-0002-4963-4173

Recebido em 17 de fevereiro de 2019

Aceito para publicação em 01 de abril de 2019

Publicado em XX de XXX de 2019 